\title{
Genetic diversity of eleven European pig breeds
}

\author{
Guillaume LAVAL ${ }^{\mathrm{a} *}$, Nathalie IANNUCCELLI ${ }^{\mathrm{a}}$, Christian \\ LEGAUlT $^{b}$, Denis Milan ${ }^{\mathrm{a}}$, Martien A.M.GROENEN ${ }^{c}$, \\ Elisabetta GIUfFRA ${ }^{d}$, Leif ANDERSSON ${ }^{d}$, Peter H. NISSEN" \\ Claus B. JøRGENSEN ${ }^{e}$, Petra BEECKMANn ${ }^{f}$, \\ Hermann GELDERMANN ${ }^{\mathrm{f}}$, Jean-Louis FOULLEY ${ }^{\mathrm{b}}$, \\ Claude Chevaleta ${ }^{a}$, Louis OLLIVIER ${ }^{\mathrm{b}}$ \\ ${ }^{\text {a }}$ Laboratoire de génétique cellulaire, Institut national de la recherche agronomique, \\ BP 27, 31326 Castanet-Tolosan Cedex, France \\ b Station de génétique quantitative et appliquée, Institut national de la recherche \\ agronomique, 78352 Jouy-en-Josas Cedex, France \\ ${ }^{c}$ Wageningen Institute of Animal Science, Wageningen Agricultural University, \\ Wageningen, The Netherlands \\ d Department of Animal Breeding and Genetics, Swedish University \\ of Agricultural Sciences, Uppsala, Sweden \\ e Division of Animal Genetics, the Royal Veterinary and Agricultural University, \\ Copenhagen, Denmark \\ ${ }^{\mathrm{f}}$ Department of Animal Breeding and Biotechnology, Universität Hohenheim, \\ Stuttgart, Germany
}

(Received 8 July 1999; accepted 14 January 2000)

\begin{abstract}
A set of eleven pig breeds originating from six European countries, and including a small sample of wild pigs, was chosen for this study of genetic diversity. Diversity was evaluated on the basis of 18 microsatellite markers typed over a total of 483 DNA samples collected. Average breed heterozygosity varied from 0.35 to 0.60. Genotypic frequencies generally agreed with Hardy-Weinberg expectations, apart from the German Landrace and Schwäbisch-Hällisches breeds, which showed significantly reduced heterozygosity. Breed differentiation was significant as shown by the high among-breed fixation index (overall $F_{\mathrm{ST}}=0.27$ ), and confirmed by the clustering based on the genetic distances between individuals, which grouped essentially all individuals in 11 clusters corresponding to the 11 breeds. The genetic distances between breeds were first used to construct phylogenetic trees. The trees indicated that a genetic drift model might explain the divergence of the two German
\end{abstract}

* Correspondence and reprints

E-mail: glaval@toulouse.inra.fr 
breeds, but no reliable phylogeny could be inferred among the remaining breeds. The same distances were also used to measure the global diversity of the set of breeds considered, and to evaluate the marginal loss of diversity attached to each breed. In that respect, the French Basque breed appeared to be the most "unique" in the set considered. This study, which remains to be extended to a larger set of European breeds, indicates that using genetic distances between breeds of farm animals in a classical taxonomic approach may not give clear resolution, but points to their usefulness in a prospective evaluation of diversity.

genetic diversity / molecular marker / conservation / pig / European breed

Résumé - Diversité génétique de onze races porcines européennes. Un ensemble de onze races porcines en provenance de six pays européens, et incluant un petit échantillon de sangliers, a été choisi pour une étude de diversité génétique. Cette diversité a été évaluée sur la base de 18 marqueurs microsatellites typés sur un total de 483 échantillons d'ADN. Les races étudiées manifestent un taux d'hétérozygotie allant de 0,35 à 0,60 . Les locus sont en équililibre de Hardy-Weinberg à l'exception du cas des races allemandes Landrace et Schwäbisch-Hällisches, qui manifestent un déficit d'hétérozygotes. L'indice de différenciation entre races est élevé ( $F_{\mathrm{ST}}$ global de 0,27 ) et les distances génétiques entre individus permettent de les regrouper pratiquement en 11 ensembles distincts, correspondant aux 11 races considérées. Les distances génétiques entre races ont d'abord été utilisées pour construire des arbres phylogénétiques. Ces arbres suggèrent qu'un modèle de dérive génétique pourrait expliquer la divergence des deux races allemandes, mais aucune phylogénie fiable n'a pu être établie entre les races restantes. Les mêmes distances ont ensuite été utilisées pour mesurer la diversité génétique globale de l'ensemble et évaluer la perte marginale de diversité associée à chacune des races étudiées. De ce point de vue, la race française Basque apparaît comme la plus originale dans l'ensemble considéré. Cette étude, qui reste à étendre à un plus grand nombre de races européennes, indique que l'utilisation des distances entre races animales domestiques dans une approche taxonomique classique risque d'avoir un faible pouvoir de résolution, mais elle souligne l'intérêt de les utiliser plutôt pour des évaluations prospectives de diversité.

diversité génétique / marqueur moléculaire / conservation / porc / race européenne

\section{INTRODUCTION}

Europe contains a large proportion of the pig world population (circa 30\%) as well as of the pig world genetic diversity ( $37 \%$ of the breeds included in the FAO inventory, according to Scherf [25]). However, the European pig industry relies predominantly on a limited number of breeds, since one single breed, the widely known Yorkshire (Large White in many countries), represents about one third of the slaughter pig's gene pool of the European Union. Europe thus needs sources of novel genetic variation in order to improve commercial lines, as exemplified by the Chinese Meishan breed included in several synthetic lines. Also, novel genetic variants may be needed in order to respond to changes in consumer demand or to be integrated in sustainable agricultural systems.

Conservation programmes, using both in situ and ex situ techniques, are already under way in several European countries. In particular, gene banks are currently being developed, though there are few for the pig. The need for 
quantifying biodiversity in order to better rationalize conservation policies is recognized (see Weitzman [32]).

In order to facilitate and rationalize the maintenance of pig genetic diversity, it is essential that simple assays be quickly developed taking advantage of the molecular genetics tools now available. Such tools have recently been developed through progress made in genome studies and genotyping technologies. Major contributions to the making of genetic maps have been made through the EC-co-ordinated Pig Gene Mapping Project (PiGMaP) over the period 19911996 (Archibald et al. [2]). In the second phase of this project, covering the period 1994-1996, a pilot study on genetic diversity was planned (Archibald [1]), along the recommendations made in 1993 to FAO by a working group (Barker et al. [4]). The results obtained are presented in this paper, and conclusions for further investigations are discussed.

\section{MATERIALS AND METHODS}

\subsection{The breeds sampled}

In order to sample the European pig diversity, an initial set of 12 breeds belonging to 7 different countries was identified and animals were selected according to the following sampling protocol. In large breeds, the sampling objective was 50 animals (25 males, 25 females) unrelated at the grandparental level. For smaller breeds, as this was often not possible, the objective was a male and a female from each of 25 litters, each litter being farrowed by a different female, and the 25 litters representing as many different sires as possible. The 7 laboratories involved in the study were responsible for blood collection and preparation of the DNA samples in the breed(s) of their respective countries.

The 12 breeds of the study are listed in [1] (Tab. of p. 200). The Tamworth breed was eventually not sampled, and the remaining set in this analysis therefore included 11 breeds, originating from 6 countries. Table I gives the list of those breeds, the codes used in the following presentation and the sizes of the samples. It can be seen that the objective of 50 pigs per breed was only reached (or approached) in the first 8 breeds of Table I. It should also be mentioned that the Wild Pig sample provided by Sweden (SEWP) came from wild animals hunted in Poland. For that reason, this population could not be sampled according to the rules applied in domestic breeds. Finally a total of 483 DNA samples were collected (see Tab. I).

General information on those breeds is entered in the Animal Genetic Data Bank of the European Association for Animal Production (EAAP-AGDB). This information may be found in [26] and at http://www.tiho-hannover.de/einricht/zucht/eaap/index.htm. Similar information may be found in the FAO Domestic Animal Diversity Information System (DAD-IS: see [25] and http://www.fao.org/dad-is/). 
Table I. Distribution of the breeds sampled in the European countries. (Numbers in parentheses for total males and females assume equal numbers of each sex for the SELR and SEWP).

\begin{tabular}{llllll}
\hline \multirow{2}{*}{ Country } & \multicolumn{1}{c}{ Breed name } & $\begin{array}{l}\text { Country-breed code } \\
\text { (entry number }\end{array}$ & \multicolumn{2}{c}{ Number of DNA samples } \\
\cline { 5 - 6 } & & in EAAP-AGDB) & M & F & Total \\
\hline Belgium & Piétrain & BEPI (988) & 25 & 25 & 50 \\
Denmark & Sortbroget & DKSO (1005) & 14 & 45 & 59 \\
France & Basque & FRBA (987) & 22 & 25 & 47 \\
France & Gascon & FRGA (935) & 25 & 31 & 56 \\
France & Limousin & FRLI (967) & 27 & 29 & 56 \\
France & Normand & FRNO (982) & 21 & 31 & 52 \\
& (or Blanc de l'Ouest) & & & & \\
Germany & German Landrace & DELR (918) & 25 & 25 & 50 \\
Germany & Schwäbisch-Hällisches & DESH (997) & 20 & 25 & 45 \\
The Netherlands & Great Yorkshire & NLLW (938) & 21 & 11 & 32 \\
Sweden & Swedish Landrace & SELR (not entered) & - & - & 24 \\
Sweden & European Wild Pig & SEWP (not entered) & - & - & 12 \\
\hline Total & & & $200(218)$ & $247(265)$ & 483 \\
\hline
\end{tabular}

\subsection{The panel of microsatellite markers selected and the typings}

A panel of microsatellite markers was selected by D. Milan (INRA) and M. Groenen (WAU), following the FAO recommendations for diversity analyses [4], and further approved by the FAO-ISAG Advisory Committee for genetic distance studies. The markers were chosen for their quality, polymorphism, and absence of null alleles at the time of selection. At least one marker on each chromosome was selected, apart from chromosome 18 (see Tab. II). When two markers were on the same chromosome, they were chosen with a minimal distance of $30 \mathrm{cM}$ (for more information on the panel see http://www.toulouse.inra.fr/lgc/pig/panel.html). Table II also gives the numbers of alleles per locus in this set, which are on average markedly above those found in the reference families of [2] and [23].

The typings of the DNA samples were distributed among the five following laboratories: Castanet-Tolosan (Toulouse) for the four FR breeds and the BEPI, Wageningen for the NLLW, Hohenheim (Stuttgart) for the two DE breeds, Copenhagen for the DKSO and Uppsala for the SELR and SEWP breeds. All laboratories used automated ABI sequencers with fluorescent dyes, apart from the Hohenheim Laboratory where an ALF automated sequencer was used.

For further standardization of genotypes, 4 control animals were analysed either on the same gels (FR, BE, NL, DK, SE), or on control gels (DE). These 4 animals were chosen from the PiGMaP reference families [2], namely 2 French F1 animals from a Large White $\times$ Meishan cross and 2 Swedish F1 animals from a Wild Pig $\times$ Large White cross. 
Table II. The panel of markers.

\begin{tabular}{|c|c|c|c|c|}
\hline \multirow{2}{*}{$\begin{array}{l}\text { Chromosome } \\
\text { arm }\end{array}$} & \multirow[t]{2}{*}{ Marker } & \multicolumn{2}{|c|}{$\mathrm{Nb}$ of alleles } & \multirow{2}{*}{$\begin{array}{c}\mathrm{Nb} \text { of individuals } \\
\text { unambiguously genotypec }\end{array}$} \\
\hline & & $(1)$ & (2) & \\
\hline $1 p$ & CGA & 12 & 20 & $\mathrm{D}^{\mathrm{a}}$ \\
\hline $1 q$ & S0155 & 6 & 7 & 464 \\
\hline $2 p$ & SW240 & 8 & 11 & 463 \\
\hline $2 q$ & S0226 & 9 & 13 & 460 \\
\hline $3 p$ & SW72 & 8 & 9 & $\mathrm{D}$ \\
\hline $3 q$ & S0002 & 7 & 16 & 395 \\
\hline $4 p$ & S0227 & 10 & 8 & 465 \\
\hline $5 q$ & S0005 & 7 & 20 & 440 \\
\hline $5 q$ & IGF1 & 10 & 12 & 451 \\
\hline $6 q$ & SW122 & 10 & 9 & 459 \\
\hline $6 q$ & S0228 & 12 & 10 & $\mathrm{D}$ \\
\hline $7 q$ & SW632 & 6 & 13 & 466 \\
\hline $7 q$ & S0101 & 9 & 8 & $\mathrm{D}$ \\
\hline $8 \mathrm{q}$ & S0225 & 8 & 10 & 467 \\
\hline $8 \mathrm{q}$ & S0178 & 4 & 11 & 454 \\
\hline $9 p$ & SW911 & 9 & 9 & 462 \\
\hline $10 \mathrm{q}$ & SW951 & 5 & 4 & 462 \\
\hline $11 q$ & S0386 & 10 & 8 & $\mathrm{D}$ \\
\hline $12 q$ & S0090 & 4 & 8 & 461 \\
\hline $13 q$ & S0068 & 9 & 16 & $\mathrm{D}$ \\
\hline $13 q$ & S0215 & 10 & 8 & 456 \\
\hline $14 q$ & SW857 & 6 & 9 & 456 \\
\hline $15 q$ & S0355 & 14 & 8 & $\mathrm{D}$ \\
\hline $15 q$ & SW936 & 13 & 11 & $\mathrm{D}$ \\
\hline $16 q$ & S0026 & 8 & 7 & $\mathrm{D}$ \\
\hline $17 q$ & SW24 & 8 & 13 & 455 \\
\hline $\mathrm{Xq}$ & S0218 & 8 & 9 & 451 \\
\hline TOTAL (Mean) & 27 & $230(8.5)$ & $287(10.6)$ & $8187(455)$ \\
\hline
\end{tabular}

(1) PiGMaP (Archibald et al. [2]) and USDA (Rohrer et al. [23]) reference families. (2) Present study. ${ }^{\mathrm{a}} \mathrm{D}$ : Marker discarded because no individual could be unambiguously genotyped in one or several breeds. 
Moreover, to avoid differences in primer synthesis, all laboratories used primers from a single synthesis provided by Max Rothschild (Ames, Iowa). Raw data (allele size) were collected in Toulouse for identification of genotypes (allele reference sizes are available at http://www.toulouse.inra.fr/lgc/pig /panel/refsize.htm).

In spite of the standardization, it was not always possible to unambiguously identify the genotypes analysed in 5 different laboratory conditions. Thus the number of genotypes identified was generally variable across breeds and loci, and the genotype could not be determined for some breed-marker combinations (see Tab. II). In particular, genotypes could not be unambiguously identified for 7 markers (SW72, S0228, S0101, S0386, S0068, S0355, SW936) in DELR and DESH. In addition, the CGA locus exhibited very long alleles that could not be resolved in most breeds and also had to be discarded. As a result, only 18 loci could be used for comparing the breeds. Finally, out of the 483 DNA samples collected a maximum of 467 animals could be used in the genetic analyses (see Tab. II).

\subsection{Genetic analysis}

\subsubsection{Within-breed diversity}

Observed heterozygosities and their unbiased estimates taking account of sample sizes were computed per autosomal locus and per breed, according to the method described in [6]. An exact test of Hardy-Weinberg equilibrium was performed (GENEPOP [20]), with a Bonferoni correction for repeated tests over 187 breed-locus combinations. The exact $\mathrm{P}$-value was obtained either by the complete enumeration method [15] for loci with fewer than five alleles, or by the Markov Chain method of [12] otherwise.

\subsubsection{Between-breed diversity}

Breed differentiation was evaluated by the fixation indices of Wright (see [30] and [22]). The null hypothesis of random mating within and between populations was tested by means of permutation tests (allele permutation within population to test for $F_{\mathrm{IS}}$, and individual permutation between populations to test for $F_{\mathrm{ST}}$ ) as shown by [6].

Genetic distances between individuals were estimated on the basis of their own genotypes, using a multi-locus estimation of the kinship coefficients. This between individual genetic distance $D_{\mathrm{BI}}$ is defined as $D_{\mathrm{BI}}=1-P$ [drawing two identica1 alleles from the two individuals] $[7,8]$, setting $D_{\mathrm{BI}}=0$, however, when the two individuals have identical genotypes.

Genetic distances between breeds were calculated based on the allelic frequencies in each breed, or in each breed-sex combination with appropriate weight for the $\mathrm{X}$-linked marker (1/3 for males and $2 / 3$ for females). An equal number of males and females was assumed in the 2 breeds (SELR and SEWP) in which the sex was not identified. Two measures of distances were used, namely the Reynolds' [21] and the standard Nei's distances [17], taking account of the corrections needed for small sample size [18]. 


\subsubsection{Clustering, phylogenetic tree reconstruction and measures of breed diversity}

Distances between individuals were used to infer phylogenies by the unweighted pair-group method with arithmetic mean (UPGMA) described in [13], [27] and [5]. Distances between breeds were also used for tree construction according to the neighbour-joining algorithm of [24], giving unrooted trees. The bootstrapping procedure of PHYLIP [9] was used to evaluate the significance of tree nodes and was extended to account for unequal sample size across breeds and loci.

Genetic distances can also be used to measure diversity, as proposed by Weitzman [31, 32]. This approach has been implemented here to provide a further upward hierarchical representation of the breeds and to evaluate marginal losses of diversity due to various patterns of breed extinction, as advocated by [28].

\section{RESULTS}

\subsection{Heterozygosity and deviation from Hardy-Weinberg equilibrium}

For each breed, Table III shows the observed and expected heterozygosities and the numbers of alleles averaged across the 17 autosomal loci. Observed heterozygosities ranged from 0.35 (for FRBA) to 0.60 (for BEPI) and average numbers of alleles from 3.22 (FRBA) to 5.72 (DESH). Three loci, S0215, S0225

Table III. Average within-breed marker polymorphism (17 autosomal loci).

\begin{tabular}{cccccccc}
\hline Breed & $\begin{array}{c}\text { Number } \\
\text { genotyped } \\
\text { (range across } \\
\text { loci) }\end{array}$ & \multicolumn{2}{c}{ Heterozygosity } & $\begin{array}{c}\text { Average number of } \\
\text { alleles }\end{array}$ & $\begin{array}{c}\text { Test of } \\
\text { H.W. } \\
\text { equilibrium }\end{array}$ & $N_{\mathrm{e}}^{\mathrm{b}}$ \\
\cline { 3 - 6 } Observed & Expected & Observed Effective & & \\
\hline BEPI & $40-46$ & 0.60 & 0.59 & 5.33 & 2.44 & NS & 32686 \\
DKSO & $47-50$ & 0.53 & 0.55 & 5.17 & 2.22 & NS & 44 \\
FRBA & $40-46$ & 0.35 & 0.35 & 3.22 & 1.54 & NS & 13 \\
FRGA & $18-56$ & 0.47 & 0.50 & 4.05 & 2 & NS & 28 \\
FRLI & $41-56$ & 0.43 & 0.44 & 3.70 & 1.78 & NS & 13 \\
FRNO & $33-52$ & 0.50 & 0.50 & 4.28 & 2. & NS & 33 \\
DELR & $38-50$ & 0.54 & 0.62 & 5.61 & 2.63 & $*(0.15)$ & 1837 \\
DESH & $41-45$ & 0.53 & 0.66 & 5.72 & 2.94 & $*(0.20)$ & 128 \\
NLLW & $28-30$ & 0.51 & 0.50 & 4.11 & 2 & NS & 7368 \\
SELR & $20-24$ & 0.57 & 0.57 & 4.78 & 2.32 & NS & - \\
SEWP & $9-12$ & 0.58 & 0.59 & 4.55 & 2.44 & NS & - \\
\hline
\end{tabular}

${ }^{a}$ NS: not significant ; ${ }^{*}: P<0.05$ and value of $F_{\text {IS }}$ (Weir and Cockerham [29]).

b $N_{\mathrm{e}}$ : effective population size given in Simon and Buchenauer [25]. 
and SW951, were fixed in 6, 2 and 1 of our breeds respectively, and the 2 loci of chromosome 5, S0005 and IGF1, reached a 0.92 observed heterozygosity in the wild pig sample. The heterozygosities observed are close to their expectations in all breeds except in DELR and DESH which show a markedly reduced heterozygosity.

Deviations from Hardy-Weinberg equilibrium are significant for 8 locusbreed combinations out of 187 , which represents a percentage slightly below the $5 \%$ expected in such a number of tests under the hypothesis of equilibrium.

However the deviations are all observed in DESH and DELR, which are the only two breeds showing a globally significant deviation. In both cases, deviation from Hardy-Weinberg equilibrium is linked to a quite high positive $F_{\text {IS. }}$. Table III also shows that the breeds vary relatively more in effective size than in heterozygosity. However, the significant rank correlation (0.8) between population size and heterozygosity among the breeds in Table II indicates a tendency for a positive association.

\subsection{Breed differentiation and genetic distances}

The fixation indices of Table IV show a generally high level of genetic differentiation between breeds, with quite large differences across loci.

Table IV. Fixation indices per locus (Weir and Cockerham [30]; standard error in parentheses).

\begin{tabular}{ccccc}
\hline Chromosome & Locus & $F_{\text {IS }}$ & $F_{\text {IT }}$ & $F_{\text {ST }}$ \\
\hline 1 & S0155 & $0.040(0.028)$ & $0.284(0.075)$ & $0.254(0.087)$ \\
2 & SW240 & $0.028(0.057)$ & $0.190(0.083)$ & $0.167(0.063)$ \\
2 & S0226 & $0.105(0.078)$ & $0.374(0.075)$ & $0.300(0.068)$ \\
3 & S0002 & $0.007(0.010)$ & $0.247(0.063)$ & $0.242(0.060)$ \\
4 & S0227 & $0.239(0.117)$ & $0.327(0.093)$ & $0.116(0.034)$ \\
5 & S0005 & $-0.009(0.029)$ & $0.185(0.034)$ & $0.193(0.026)$ \\
5 & IGF1 & $-0.018(0.061)$ & $0.165(0.064)$ & $0.180(0.041)$ \\
6 & SW122 & $-0.002(0.053)$ & $0.138(0.043)$ & $0.140(0.028)$ \\
7 & SW632 & $0.115(0.080)$ & $0.360(0.059)$ & $0.277(0.053)$ \\
8 & S0225 & $0.146(0.041)$ & $0.458(0.123)$ & $0.365(0.120)$ \\
8 & S0178 & $0.024(0.028)$ & $0.154(0.042)$ & $0.133(0.037)$ \\
9 & SW911 & $0.070(0.057)$ & $0.362(0.075)$ & $0.314(0.080)$ \\
10 & SW951 & $0.128(0.061)$ & $0.409(0.043)$ & $0.321(0.066)$ \\
12 & S0090 & $0.018(0.044)$ & $0.375(0.095)$ & $0.363(0.088)$ \\
13 & S0215 & $0.218(0.081)$ & $0.794(0.116)$ & $0.737(0.160)$ \\
14 & SW857 & $0.068(0.034)$ & $0.328(0.069)$ & $0.279(0.077)$ \\
17 & SW24 & $0.060(0.037)$ & $0.367(0.036)$ & $0.327(0.038)$ \\
X & S0218 & $0.090(0.115)$ & $0.310(0.119)$ & $0.243(0.080)$ \\
\hline
\end{tabular}




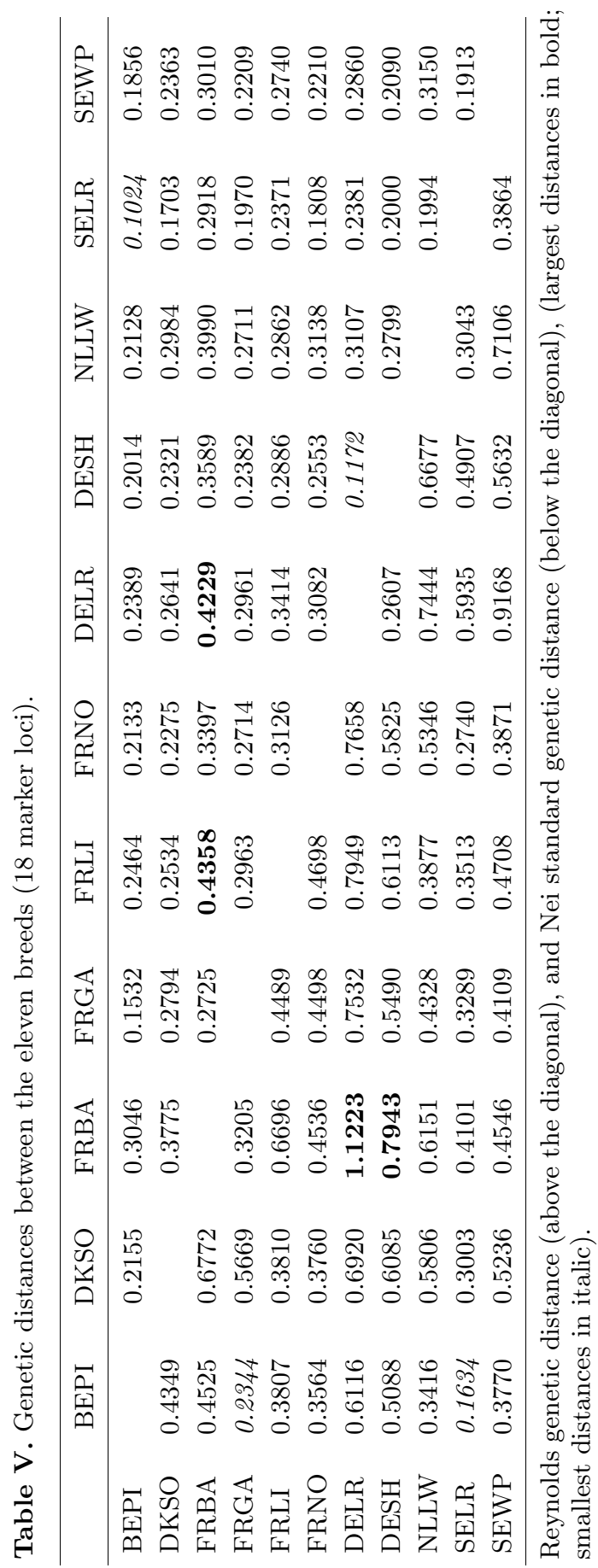


After 5000 permutations, performed with GENETIX [6], all $F_{\mathrm{ST}}$ calculated by pair of breeds are significantly different from $0(P<0.0002)$. Table $\mathrm{V}$ gives the Reynolds's and Nei's standard genetic distances. The two smallest distances are obtained for the pairs BEPI-SELR (with both distances) and either DESHDELR for Reynolds or BEPI-FRGA for Nei standard. The two largest distances are between FRBA on one hand and, on the other hand, either FRLI and DELR for Reynolds or DELR and DESH for Nei standard.

\subsection{Clustering and phylogenetic trees}

The between individuals UPGMA tree of Figure 1 shows eleven clusters grouping the individuals which belong to the same breed. The only exceptions are an exchange between DESH and DELR and a DESH individual which does not fit in with any breed.

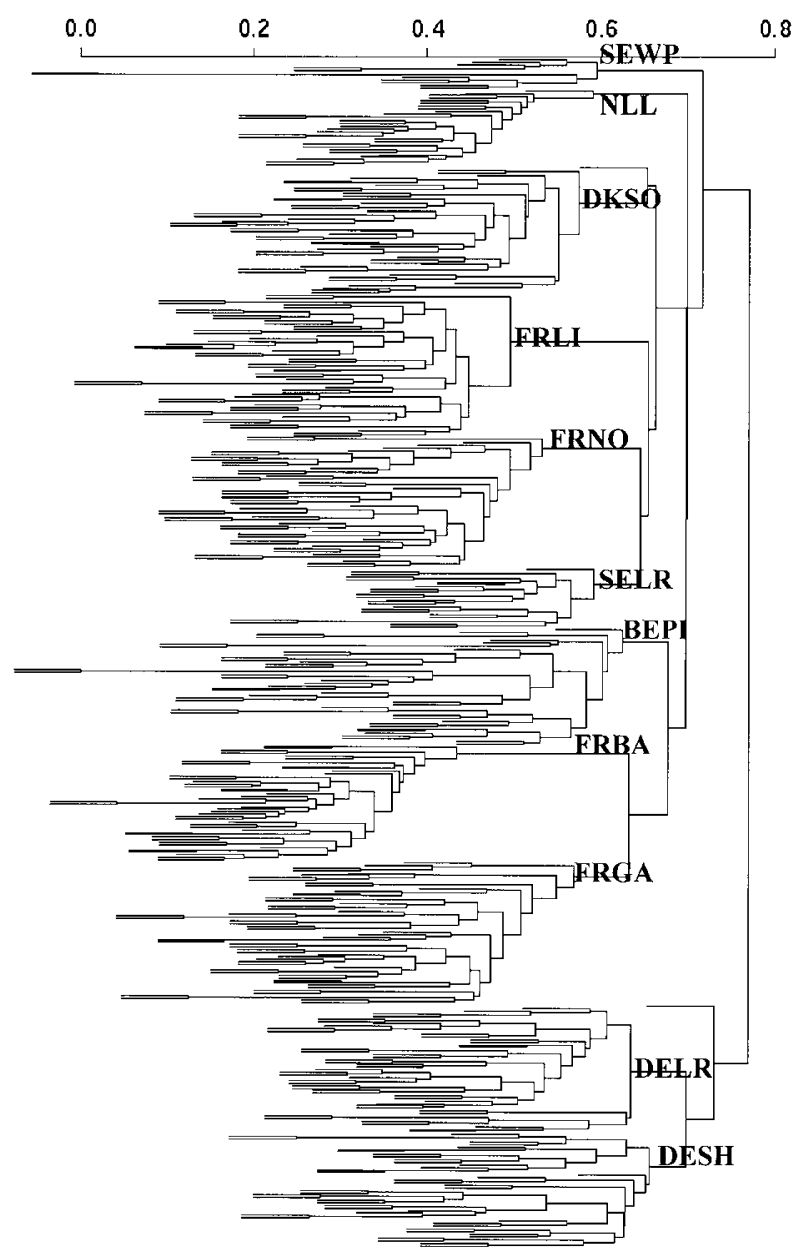

Figure 1. Hierarchical clustering based on genetic distances between individuals. 
The neighbor-joining trees based on both distances indicate that, apart from the two German breeds, no reliable phylogeny can be inferred since only the node linking the two German breeds shows a bootstrap value (of 90\%) close to significance. When the analysis was restricted to the 9 breeds for which genotypes were available at 25 loci (thus excluding the two German breeds), even lower bootstrap values were obtained (results not shown). This suggests that no reliable phylogeny can be constructed among those breeds, as if they had differentiated according to a radiative scheme of divergence. In an analysis restricted to the ten domestic breeds, after excluding the small sample of wild pigs, the phylogeny of Figure 2 was obtained, further confirming a radiative scheme of divergence.

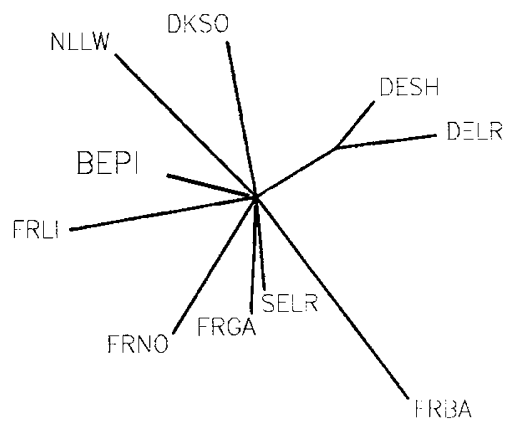

Figure 2. Neighbor-joining tree of the ten domestic breeds.

\subsection{Distribution and amount of diversity}

The Weitzmann representation, based on the Reynolds distance, is shown in Figure 3, in which the branch length of each breed can be read as approximately measuring its relative contribution to the corresponding diversity function. The marginal losses of diversity attached to each breed, which may be taken as a measure of their "uniqueness", are shown in Table VI, based on the two distances considered. On average, the highest and lowest losses of diversity are incurred with the extinction of the Basque or the Piétrain breeds, respectively. It can also be seen from Table VI that the loss of the two German breeds (DELR and DESH) induces a markedly higher loss than the sum of the corresponding individual breed losses, whereas the losses attached to two French local breeds (FRBA and FRLI) add up almost exactly.

\section{DISCUSSION}

\subsection{Within population structure}

In these European pig breeds, average heterozygosity observed is around 0.5 (Tab. III). This level of polymorphism is similar to the values so far reported for microsatellites in European pig and cattle breeds, e.g. by [10], [29] and [16], but below the values observed in human or chimpanzee populations where the expected heterozygosity ranges from 0.7 to 0.9 [11]. 


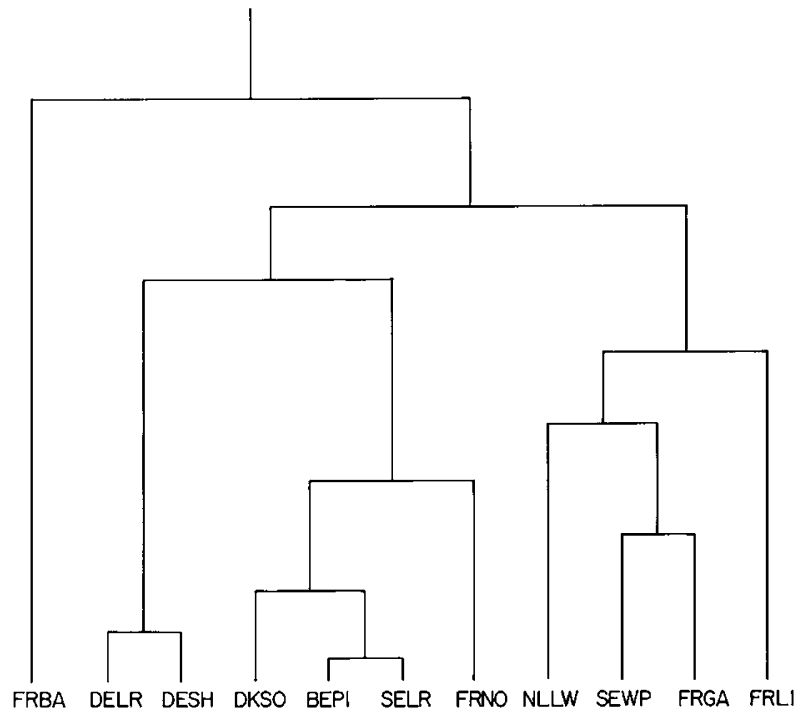

Figure 3. Dendrogram of relationship established by the method of Weitzman [31] using the Reynolds pairwise distances among the ten domestic breeds and the wild pig.

This level of polymorphism when compared to the corresponding effective sizes of the breeds, ranging from 13 to over 30000 (Tab. III), cannot be seen as the result of an equilibrium between drift and mutation. Under such a model, assuming a mutation rate $u$ of about $10^{-4}$ for microsatellites and with the effective sizes of Table III, $4 N_{e} u$ should vary from 0.005 to 13 and the equilibrium values of heterozygosities would be expected to vary from 0.005 to 0.93. This contrast with the observed values, though based on current effective sizes which may not reflect past ones, tends to confirm that standard population genetics models cannot be easily extended to sets of breeds of farm animals; probably because they cannot be considered as separate closed populations.

Since the 27 markers were selected, null alleles have been identified in other familial studies: for instance S0215 (Moser et al. unpublished), and S0386 (Archibald et al., personal communication). However, our study did not provide any evidence of null alleles since 179 breed-locus combinations out of 187 may be considered as being in Hardy-Weinberg equilibrium. Therefore, if null alleles existed in our breeds their frequencies would probably be low and would not greatly distort the genotypic frequencies. In addition, all loci showing a significant deviation from random union of gametes belonged to the two German breeds. This suggests some inbreeding effect, counterbalanced by high numbers of alleles (yielding a high expected heterozygosity), though the presence of null alleles only in these breeds cannot be excluded.

\subsection{Genetic structure of the 11 breeds sampled}

The microsatellites used did not exhibit any breed specific allele allowing simple identification of the breed to which each animal belonged. However, 
the UPGMA tree of individuals is in very good agreement with the breed structure (Fig. 1). More precisely, using breed allelic frequencies to calculate the likelihood that an animal belongs to a given breed and then assigning the animal to the breed showing the largest likelihood (as proposed by Paetkau et al. [19]) allowed all animals to be correctly assigned. In most cases this result was obtained because an individual from one breed carried at least one allele which was absent in the other breeds. This indicates that these markers provide a way of measuring the genetic differentiation between the breeds considered. This strong differentiation is also confirmed by the very large $F_{\mathrm{ST}}$ values of Table IV.

Neglecting the effects of migration, and assuming a low contribution of mutations to the genetic diversity between these breeds, the differences in allelic frequencies may be interpreted as primarily due to random genetic drift. The genetic differentiation may be seen as the result of an increased mean inbreeding coefficient $F$ over a rather recent period of time. Under this hypothesis, the most appropriate measure of diversification is provided by the Reynolds distance. This distance has an expected value of $0.5\left(F_{1}+F_{2}\right)$, where $F_{1}$ and $F_{2}$ are the increases of inbreeding since divergence, or, more generally the average $F_{i}$, with, $F_{i}=1-\left(1-\frac{1}{2 N_{i}}\right)^{n}, i=1,2$, assuming $n$ generations of divergence and a constant effective size $N_{i}$.

The tree of Figure 2 shows that DESH and DELR are closely related. The high distances separating them from the other breeds and their higher numbers of alleles suggest that genetic drift might have structured these breeds into 2 groups, a group of German breeds and another group of non-German breeds among which it is difficult to distinguish any particular structure. The assumption of a radiative divergence of the non-German breeds agrees with the tentative phylogeny of Figure 2, which may sum up our interpretation of the genetic differences observed between these European breeds. On the other hand, the dendrogram of Figure 3 could suggest the existence of a distinct subset of breeds belonging to the Landrace family, extending from the DELR to the FRNO branches. These interpretations are of course limited to the ten domestic breeds available in this study and they would obviously need to be confirmed on a larger set.

\subsection{Breed diversity}

This study gave an opportunity for evaluating the global diversity of the set of breeds considered, using the approach of Weitzman [31, 32]. Table VI clearly shows the wide range of the contributions of each breed to the overall diversity, ranging from about 4 to $15 \%$. Table VI also shows that the results are not entirely consistent over the 2 measurements of genetic distances used. It can be noted that the Reynolds distance appears to be slightly more discriminating between breeds, since contributions range from 4 to $17 \%$. Based on this distance, the 4 French local breeds altogether account for half of the total diversity, which is an indication of the potential value of preserving local endangered breeds in the maintenance of a species biodiversity. But, here again, our conclusions should be considered as relative to the limited sample of breeds 
considered, and do not preclude conclusions which might be obtained on a more comprehensive set of breeds.

\section{CONCLUSIONS}

This study may be one of the first demonstrations of the feasibility of evaluating genetic diversity across different countries following the FAO recommendations [4]. An evaluation of buffalo genetic diversity along the same lines by Barker et al. [3] is also to be mentioned. Once an agreement is reached on a common set of markers, the essential requirements for achieving comparability of allele sizing between different laboratories are (i) to include on the same gel a set of common control DNA samples previously distributed to the participants, and (ii) to preferably use primers derived from a single synthesis, as done in the present experiment. For further studies, we strongly suggest use of DNA from the control animals mentioned before, which are available upon request to L. Andersson and D. Milan.

The panel of markers used in this trial exhibited a very high polymorphism, confirming an early study of microsatellite polymorphisms in 4 major pig breeds by [10] and the study on Belgian pig breeds of [29]. There are also good indications that null alleles were at a low frequency in the samples investigated. The 11 breeds chosen exhibit a very strong differentiation. In spite of this, it appeared difficult to infer any reliable phylogeny among those populations. This may not be too surprising given that our present domestic breeds are not likely to have resulted from a strict tree-like branching process, as noted by [28]. On the other hand, there is a need for measuring the overall diversity of a set of breeds, since prospective evaluations of diversity are required for defining appropriate conservation policies, as advocated by [32]. Such an approach may be based on standard genetic distances, which is the Weitzman approach, though similar procedures may also be implemented from contingency tables of allelic frequencies, as shown by [14]. Our results certainly point to the usefulness of global evaluations of diversity using molecular markers for the choice of breeds worthy of preservation. However, as stressed by [4], final decisions should take into account additional information on traits of economic importance and on specific adaptive features.

\section{ACKNOWLEDGEMENTS}

This project was essentially supported by the EC Biotechnology programme (PiGMaP contract BIO2-CT94-3044, coordinated by A. Archibald). Complementary support was provided by the EC Framework IV programme (contract BIO4-CT98-0188). Additional financial support from the French Ministry of Agriculture is also gratefully acknowledged.

The DNA samples from the Piétrain breed were prepared by Alex van De Weghe and Luc Peelman (Ghent, Belgium). The sampling and DNA preparation for the French samples are due to the cooperative efforts of D. Brault, G. Burgaud, J.C. Caritez and J. Gruand (INRA) and M. Luquet and F. Labroue (Institut technique du porc). 
We thank Prof. Max Rothschild (Ames, Iowa), US Pig Genome Co-ordinator, for having freely provided the primers to the five typing laboratories in this project.

Comments made by two anonymous referees are also gratefully acknowledged.

\section{REFERENCES}

[1] Archibald A., The pig gene mapping project (PiGMaP) - identifying trait genes, in: Hoeveler A., Cresti M. (Eds.), Biotechnology (1992-1994) Final Report, Office for Official Publications of the European Communities, Luxembourg, 1997, vol. 2, pp. 193-207.

[2] Archibald A., Haley C.S., Brown J., Couperwhite S., Mc Queen H.A., et al., The PiGMaP consortium linkage map of the pig (Sus scrofa), Mamm. Genome 6 (1995) 157-175.

[3] Barker J.S.F., Moore S.S., Hetzel D.J.S., Evans D., Tan S.G., Byrne K., Genetic diversity of Asian water buffalo (Bubalus bubalis): microsatellite variation and a comparison with protein-coding loci, Anim. Genet. 28 (1997) 103-115.

[4] Barker J.S.F., Hill W.G., Bradley D., Nei M., Fries R., Wayne R.K., Measurement of domestic animal diversity (MoDAD): original working group report, FAO, Rome, 1998.

[5] Becker R.A., Chambers J.M., Wilks A.R., The New S Language, Wadsworth and Brooks/Cole, Pacific Grove, California, 1988.

[6] Belkhir K., Borsa P., Goudet J., Chikhi L., Bonhomme F., GENETIX, logiciel sous WindowsTM pour la génétique des populations, Laboratoire génome et populations, CNRS UPR 9060, Université de Montpellier II, Montpellier (France) (1998).

[7] Branlard G., Chevalet C., Sur la diversité des blés tendres cultivés en France, Agronomie 4 (1984) 933-938.

[8] Chevalet C., Calcul des coefficients d'identité, inégalités et distances génétiques, in: Legay J.M. (Eds.), Biométrie et Génétique, Soc. Fr. Biom. INRA (1980) pp. 42-49.

[9] Felsenstein J., PHYLIP (Phylogeny Inference Package) Version 3.5, Department of Genetics, University of Washington, Seattle, 1993.

[10] Fredholm M., Winterø A.K., Christensen K., Kristensen B., Nielsen P.B., Davies W., Archibald A., Characterization of twenty four porcine $(\mathrm{dA}-\mathrm{dC}) \mathrm{n}-$ $(\mathrm{cT}-\mathrm{cG}) \mathrm{n}$ microsatellites: Genotyping of unrelated animals from four breeds and linkage studies, Mamm. Genome 4 (1993) 187-192.

[11] Garza J.C., Montgomery S., Freimer N.B., Microsatellite allele frequencies in humans and chimpanzees with implications for constraints on allele size, Mol. Biol. Evol. 12 (1995) 594-603.

[12] Guo S.W., Thompson E.A., Performing the exact test of Hardy-Weinberg proportions for multiple alleles, Biometrics 48 (1992) 361-372.

[13] Hartl D.L., Clark A.G., Principles of Population Genetics, 3rd edn., Sinauer, Sunderland, Massachussets, 1997.

[14] Laloë D., Moazami-Goudarzi K., Souvenir Zafrindrajaona P., Analyse des correspondances et biodiversité dans les races domestiques, Journées de la société française de Biométrie, 20-21 mai 1999, Grenoble, 5 p.

[15] Louis E.J., Dempster E.R., An exact test for Hardy-Weinberg and multiple alleles, Biometrics 43 (1987) 805-811.

[16] MacHugh D.E., Loftus R.T., Bradley D.J. Sharp P.M., Cunningham P., Microsatellite DNA variation within and among European cattle breeds, Proc. R. Soc. Lond. 256 (1994) 23-31. 
[17] Nei M., Genetic distances between populations, Am. Nat. 106 (1972) 283-292.

[18] Nei M., Estimation of average heterozygosity and genetic distance from a small number of individuals, Genetics 89 (1978) 583-590.

[19] Paetkau D., Calvert W., Stirling I., Strobeck C., Microsatellite analysis of population structure in Canadian polar bears, Mol. Ecol. 4 (1995) 347-354.

[20] Raymond M., Rousset F., GENEPOP version 3.1b. Population genetics software for exact tests and ecumenicism, J. Hered. 86 (1995) 248-249.

[21] Reynolds J., Weir B.S., Cokerham C.C., Estimation of the coancestry coefficient: basis for a short-term genetic distance, Genetics 105 (1983) 767-779.

[22] Robertson A., Hill W.G., Deviations from Hardy-Weinberg proportions: sampling variances and use in estimation of inbreeding coefficients, Genetics 107 (1984) 703-718.

[23] Rohrer G.A., Alexander L.J., Keele J.W., Smith T.P.L., Beattie C.W., A microsatellite linkage map of the porcine genome, Genetics 136 (1994) 231-245.

[24] Saitou N., Nei M., The neighbour-joining method: a new method for reconstructing phylogenetic trees, Mol. Biol. Evol. 4 (1987) 406-425.

[25] Scherf B.D., World Watch List for Domestic Animal Diversity, 2nd edn., FAO, Rome, 1995.

[26] Simon D.L., Buchenauer D., Genetic Diversity of European Livestock Breeds, EAAP publication $\mathrm{n}^{\circ}$ 66, Wageningen Pers, Wageningen, 1993.

[27] Sneath P.H.A., Sokal R.R., Numerical Taxonomy, WH Freeman, San Francisco, 1973.

[28] Thaon d'Arnoldi C., Foulley J.L., Ollivier L., An overview of the Weitzman approach to diversity, Genet. Sel. Evol. 30 (1998) 149-161.

[29] van Zeveren A., Peelman L., van de Weghe A., Bouquet Y., A genetic study of four Belgian pig populations by means of seven microsatellite loci, J. Anim. Breed. Genet. 112 (1995) 191-204.

[30] Weir B.S., Cockerham C.C., Estimating F-statistics for the analysis of population structure, Evolution 38 (1984) 1358-1370.

[31] Weitzman M.L., On diversity, Quart. J. Econ. 107 (1992) 363-405.

[32] Weitzman M.L., What to preserve? An application of diversity theory to crane conservation, Quart. J. Econ. 108 (1993) 157-183. 